\section{Check for updates}

Cite this: J. Mater. Chem. A, 2018, 6, 6882

Received 20th December 2017 Accepted 26th February 2018

DOI: $10.1039 / c 7 t a 11128 b$

rsc.li/materials-a

\title{
The effect of oxygen on the efficiency of planar p-i-n metal halide perovskite solar cells with a PEDOT:PSS hole transport layer
}

\begin{abstract}
Bardo J. Bruijnaers, ${ }^{a}$ Eric Schiepers, ${ }^{a}$ Christ H. L. Weijtens, ${ }^{a}$ Stefan C. J. Meskers, ${ }^{a}{ }^{a}$ Martijn M. Wienk ${ }^{a}$ and René A. J. Janssen (D)*ab

Poly(3,4-ethylenedioxythiophene):polystyrene sulfonate (PEDOT:PSS) is frequently used as hole transport layer in planar $\mathrm{p}-\mathrm{i}-\mathrm{n}$ perovskite solar cells. Here we show that processing of a metal halide perovskite layer on top of PEDOT:PSS via spin coating of a precursor solution chemically reduces the oxidation state of PEDOT:PSS. This reduction leads to a lowering of the work function of the PEDOT:PSS and the perovskite layer on top of it. As a consequence, the solar cells display inferior performance with a reduced open-circuit voltage and a reduced short-circuit current density, which increases sublinearly with light intensity. The reduced PEDOT:PSS can be re-oxidized by thermal annealing of the PEDOT:PSS/ perovskite layer stack in the presence of oxygen. As a consequence, thermal annealing of the perovskite layer in air provides solar cells with increased open-circuit voltage, short-circuit current density and high efficiency.
\end{abstract}

\section{Introduction}

Metal halide perovskite materials currently attract great interest for use in hybrid organic-inorganic solar cells. Methylammonium lead halides were first used in 2009 as light sensitizers of mesoporous titania $\left(\mathrm{TiO}_{2}\right)$ in photovoltaic cells comprising a liquid electrolyte, providing a power conversion efficiency (PCE) of 3.8\%. ${ }^{1}$ The introduction of a solid organic hole transport material efficiently solved the fast degradation of the liquid-electrolyte cells and led to stable photovoltaic cells with an optimized PCE of $9.7 \% .^{2}$ The use of an insulating alumina $\left(\mathrm{Al}_{2} \mathrm{O}_{3}\right)$ layer instead of the electron-transporting $\mathrm{TiO}_{2}$ layer proved that the perovskite material itself is capable of free charge generation and very efficient ambipolar charge transport. ${ }^{3}$ Recent advances have shown PCEs of over $22 \%$ for metal halide perovskites with optimized compositions and processing methods. ${ }^{4,5}$

Metal halide perovskite materials possess many desirable properties like strong absorption, low exciton binding energy for creating free charges ${ }^{6-8}$ and high charge mobilities and lifetimes. ${ }^{9}$ The fact that metal halide perovskites can be processed from solution with relative ease makes future roll-to-roll

${ }^{a}$ Molecular Materials and Nanosystems, Institute for Complex Molecular Systems, Eindhoven University of Technology, P.O. Box 513, 5600 MB Eindhoven, The Netherlands.E-mail: r.a.j.janssen@tue.nl

${ }^{b}$ Dutch Institute for Fundamental Energy Research, De Zaale 20, 5612 AJ, Eindhoven, The Netherlands

† Electronic supplementary information (ESI) available. See DOI: $10.1039 / \mathrm{c} 7 \mathrm{ta} 11128 \mathrm{~b}$ processing an attractive option. ${ }^{\mathbf{1 0 - 1 2}}$ Their versatility in composition and processing has allowed the usage of different solvents and precursor materials and even made it possible to tune the band gap of the material. ${ }^{13-23}$

Precursor and solvent combinations also allow the tuning of the morphology of the perovskite layer by influencing nucleation and crystal growth during the processing steps. ${ }^{24-27}$ The versatility in processing has led to many different processing techniques ranging from single-step solution processing, ${ }^{4,18}$ to multi-step solution processing with and without drying and anti-solvent treatments, ${ }^{28-31}$ single and multi-step thermal evaporation and even combinations of solution processing and thermal evaporation. ${ }^{32-36}$ After the deposition of the precursor materials, usually a (thermal) annealing step is used to convert the deposited layer into the desired perovskite phase and morphology. ${ }^{37-41}$ By changing the composition of the precursor solution, the crystallization process can be retarded or sped up and by combining different lead salt precursors, the layer can even be tuned to achieve a favourable morphology and smoothness of the perovskite layer for the most efficient solar cells, which is especially important in planar device configurations. ${ }^{\mathbf{2 4 , 2 6 , 4 2}}$

Here we investigate the influence of the processing atmosphere on the photovoltaic performance of planar $\mathrm{p}-\mathrm{i}-\mathrm{n}$ perovskite solar cells with poly(3,4-ethylenedioxythiophene): polystyrene sulfonate (PEDOT:PSS) as hole transport layer, methylammonium lead triiodide as semiconductor and $[6,6]$-phenyl- $\mathrm{C}_{61}$-butyric acid methyl ester (PCBM) as electron transport layer. We show that the influence of the spin coating atmosphere on the PCE is negligible, while the annealing atmosphere has a marked effect. We found that the exposure to 
oxygen during thermal annealing of the perovskite layer is critical for obtaining efficient solar cells with high open-circuit voltage $\left(V_{\text {OC }}\right)$ and short-circuit current density $\left(J_{\text {SC }}\right)$. By annealing in an inert nitrogen atmosphere, these favourable characteristics cannot be achieved. We demonstrate that the optical and electronic properties in the bulk of the perovskite layer are independent of the annealing atmosphere. Instead, a chemical reduction of the oxidation state of the PEDOT:PSS layer during the deposition of the perovskite precursor is the cause of the decreased photovoltaic performance of devices. This chemical reduction lowers the work function of the PEDOT:PSS and of the perovskite layer on top of it, reducing the built-in voltage of the cell and leading to a lower $V_{\mathrm{OC}}$. The $J_{\mathrm{SC}}$ is further reduced due to surface recombination, which causes a significant sublinear light intensity dependence of $J_{\mathrm{SC}}$ and of the external quantum efficiency (EQE) of cells annealed in nitrogen. By thermal annealing in the presence of oxygen, it is possible to restore the oxidation state and work function of PEDOT:PSS and obtain high efficient devices.

\section{Results and discussion}

The perovskite solar cell fabrication is based on a triple anion solution of methylammonium iodide (MAI), lead(II) chloride $\left(\mathrm{PbCl}_{2}\right)$ and lead(II) acetate $\left(\mathrm{Pb}(\mathrm{OAc})_{2}\right)$ in $N, N$-dimethylformamide (DMF). This solution is heated to $70{ }^{\circ} \mathrm{C}$ and spin coated dynamically onto a pre-heated $\left(100{ }^{\circ} \mathrm{C}\right)$ glass substrate with patterned indium tin oxide (ITO), covered with PEDOT:PSS. By this hot-casting method the very hygroscopic precursor salts are already converted to the perovskite during deposition, as indicated by a pronounced colour change from the yellow precursor to the brown perovskite. Even though perovskite crystals are already formed during casting, a short additional thermal annealing step, during which the colour of the perovskite layer changes from light brown to dark brown, is required to maximize the efficiency. ${ }^{42}$ The devices are completed by a PCBM electron transport layer and a LiF/Al contact. Further details of the fabrication can be found in the Experimental.

Fig. 1a shows the stabilized current density-voltage $(J-V)$ measurements under simulated AM1.5G (100 $\left.\mathrm{mW} \mathrm{cm}^{-2}\right)$ illumination of these $\mathrm{p}-\mathrm{i}-\mathrm{n}$ photovoltaic devices, when all processing steps are either done in ambient air or in an inert $\mathrm{N}_{2}$ atmosphere. The corresponding photovoltaic parameters are summarized in Table 1. Strikingly, the efficiency of cells processed under inert conditions $\left(\mathrm{N}_{2}\right.$ atmosphere, $<1$ ppm $\mathrm{O}_{2}$ and $<1$ ppm $\mathrm{H}_{2} \mathrm{O}$ ) is much lower than the PCE of the air-processed device where both $J_{\mathrm{SC}}$ and $V_{\mathrm{OC}}$ are considerably enhanced.

To identify which processing step, deposition or annealing, is most critical, devices partially processed in air and $\mathrm{N}_{2}$ have been measured (Fig. 1d). For cells deposited in $\mathrm{N}_{2}$ but annealed in air the performance is almost identical to the fully air processed device. In sharp contrast, cells cast in air but annealed in $\mathrm{N}_{2}$, resemble the fully $\mathrm{N}_{2}$-processed devices. This demonstrates that the annealing atmosphere, and not the casting atmosphere, has the largest impact on the performance.
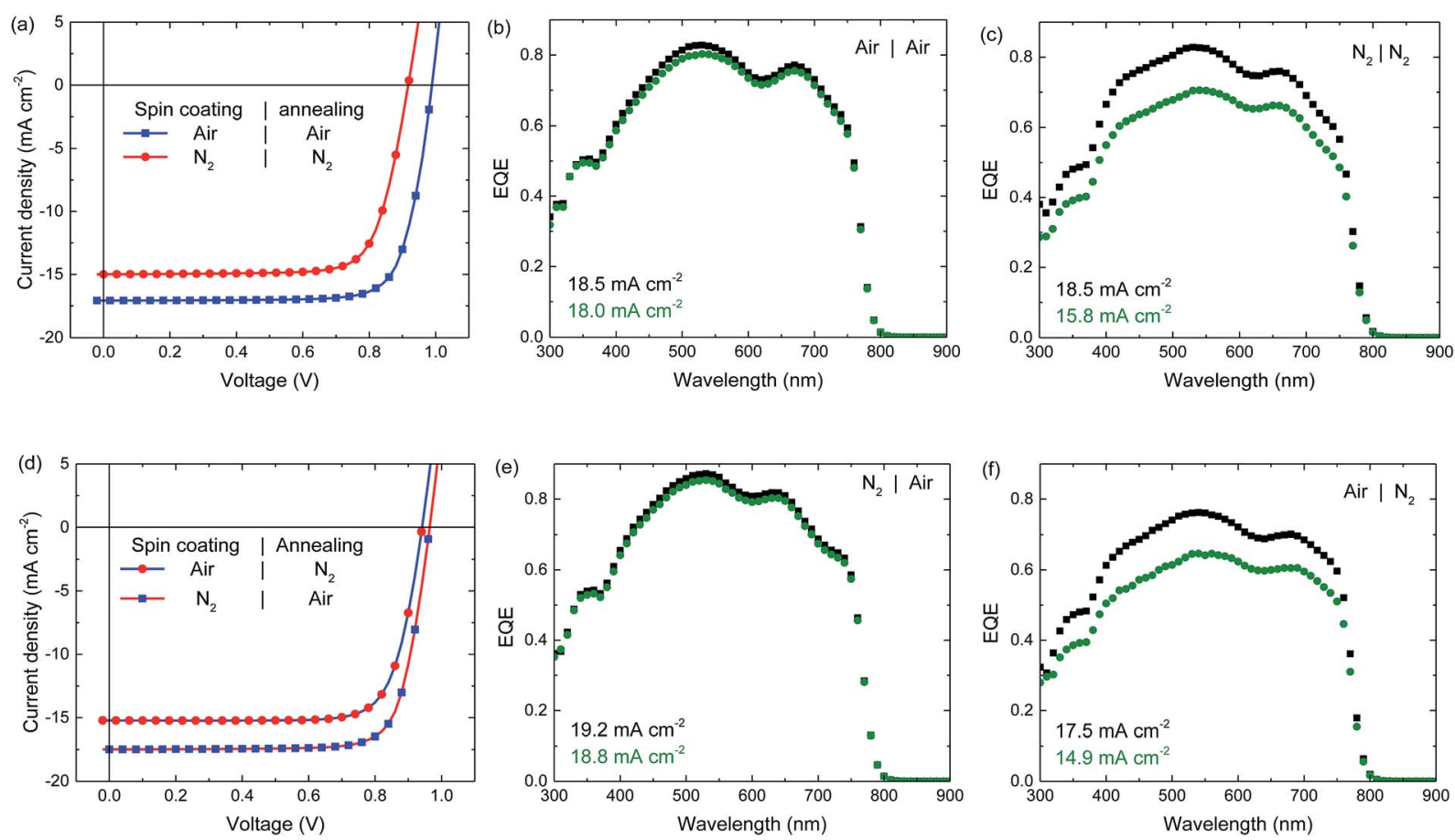

Fig. 1 Stabilized current density-voltage ( $J-V$ ) curves (a and d) under simulated AM1.5G illumination, and EQE spectra (b, $C$, e and f) of ITO/ PEDOT:PSS/perovskite/PCBM/LiF/Al solar cells processed under different atmospheres as indicated in the legends. Black squares depict the EQE under low charge carrier density (i.e. without bias illumination), green circles depict the EQE at a charge carrier density similar to that of the cell under 1 sun light intensity (i.e. with bias illumination). The integrated current density is displayed in the graphs for both measurements. The dark $J-V$ s belonging to panel (a) are displayed in the ESI, Fig. S1.† 
Table 1 Perovskite layer thickness and photovoltaic parameters of perovskite solar cells spin coated in air and $\mathrm{N}_{2}$ using the hot cast method and annealed in air, $\mathrm{N}_{2}$, dry air and humid $\mathrm{N}_{2}$

\begin{tabular}{|c|c|c|c|c|c|c|c|}
\hline $\begin{array}{l}\text { Spin coating } \\
\text { atmosphere }\end{array}$ & $\begin{array}{l}\text { Annealing } \\
\text { atmosphere }\end{array}$ & $\begin{array}{l}\text { Perovskite thickness } \\
\text { (nm) }\end{array}$ & $J_{\mathrm{SC}, J-V}\left(\mathrm{~mA} \mathrm{~cm}^{-2}\right)$ & $J_{\mathrm{SC}, \mathrm{SR} @ 1 \operatorname{sun}}\left(\mathrm{mA} \mathrm{cm}^{-2}\right)$ & $V_{\mathrm{OC}}(\mathrm{V})$ & $\mathrm{FF}$ & $\operatorname{PCE}^{a}(\%)$ \\
\hline Air & Air & 401 & 17.1 & 18.0 & 0.99 & 0.78 & 14.0 \\
\hline $\mathrm{N}_{2}$ & $\mathrm{~N}_{2}$ & 399 & 15.0 & 15.8 & 0.92 & 0.76 & 11.8 \\
\hline $\mathrm{N}_{2}$ & Air & 380 & 17.5 & 18.8 & 0.96 & 0.78 & 14.2 \\
\hline $\mathrm{N}_{2}$ & $\mathrm{~N}_{2}+\mathrm{O}_{2}$ & 368 & 18.0 & 18.4 & 0.97 & 0.76 & 13.7 \\
\hline
\end{tabular}

${ }^{a}$ The PCE has been calculated with the photocurrent determined from integrating the EQE spectrum with the AM1.5G spectrum (JSC, SR@1 sun).

The significantly lower $J_{\mathrm{SC}}$ for cells annealed in $\mathrm{N}_{2}$ was confirmed by EQE measurements under appropriate 1 sun equivalent bias light (Fig. 1b, c, e and f). Remarkably, in absence of bias light the magnitude of the EQEs of the $\mathrm{N}_{2}$-annealed cells is much higher and similar to that of the air-annealed cells. Indicating that for the samples annealed in $\mathrm{N}_{2}$ charge carrier collection is only reduced at higher charge carrier densities created by high illumination intensities.

Scanning electron microscopy (SEM) images of the top surface of the four differently processed perovskite layers (Fig. 2) indicate that the largest morphological differences can be related to the casting atmosphere. Perovskite layers cast in air possess smaller crystallites compared to those cast in $\mathrm{N}_{2}$. This could be related to a more efficient perovskite nucleation, probably due to the presence of moisture in the air. ${ }^{43}$ The distinct difference in morphology, however, does not significantly affect the device performance. The X-ray diffractograms (XRD) (Fig. 3) of these four samples are very similar, showing the same degree of preferential orientation and the presence of a small $\mathrm{PbI}_{2}$ peak for all samples. X-ray photoelectron spectroscopy (XPS) analysis on perovskite layers spin coated in $\mathrm{N}_{2}$ and annealed in either air or $\mathrm{N}_{2}$ do not show any difference in the composition of the perovskite layers and the calculated atomic $\mathrm{Pb}: \mathrm{I}$ ratio is $1: 3$ (Fig. $\mathrm{S} 2$, ESI $\dagger$ ).

Experiments so far demonstrate that exposure to air during annealing of the perovskite layer is beneficial for the device performance. Besides $\mathrm{N}_{2}$, ambient air contains oxygen and moisture, both of which have been shown to impact the properties of perovskite layers..$^{3943-45}$ To identify which component is of importance here, experiments were conducted in which the perovskite annealing in dry air (i.e. exposure to $\mathrm{O}_{2}$ but not to $\mathrm{H}_{2} \mathrm{O}$ ) was compared to annealing in humid $\mathrm{N}_{2}$ (i.e. exposure to

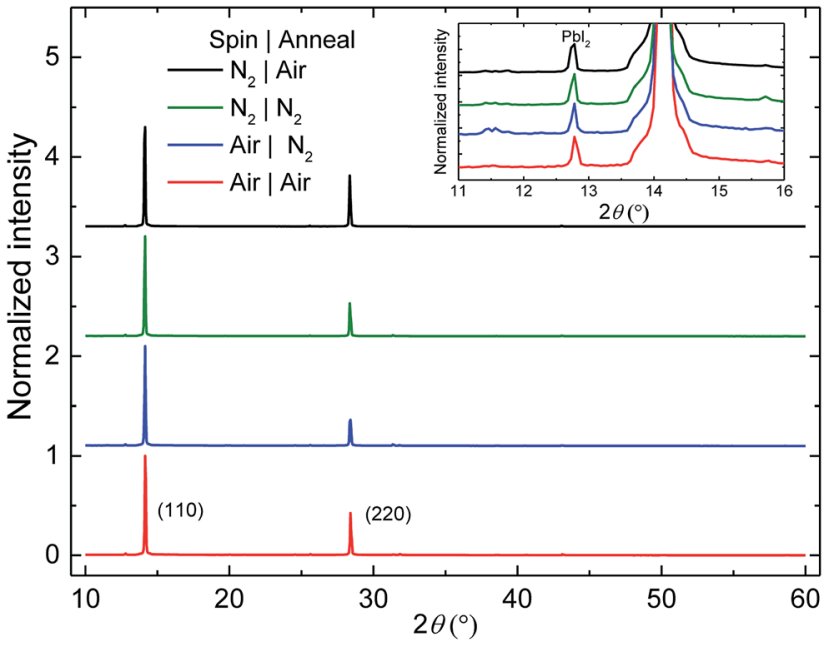

Fig. 3 X-Ray diffractograms of perovskite layers spin coated in air or $\mathrm{N}_{2}$ using the hot cast method and annealed in air or $\mathrm{N}_{2}$. The inset is a zoom and shows the presence of a small $\mathrm{Pbl}_{2}$ peak at $\sim 12.8^{\circ}$.

$\mathrm{H}_{2} \mathrm{O}$ but not to $\mathrm{O}_{2}$ ). Spin coating was done in $\mathrm{N}_{2}$ in both cases since this provides more stability of the un-annealed samples over time when stored in $\mathrm{N}_{2}$ after spin coating (Fig. S3 and S4, ESI $\dagger$ ). The perovskite layer annealed in humid $\mathrm{N}_{2}$ performs very similar to the one annealed in dry $\mathrm{N}_{2}$, displaying both a low $V_{\mathrm{OC}}$ and $J_{\mathrm{SC}}$, and a pronounced light intensity dependent EQE, indicating that water does not significantly influence the annealing process (Fig. 4a and c). The perovskite layer annealed in dry air however, performs very similarly to layers annealed in ambient air, generating a high voltage and current, and a lightintensity independent EQE (Fig. 4a and b). This demonstrates
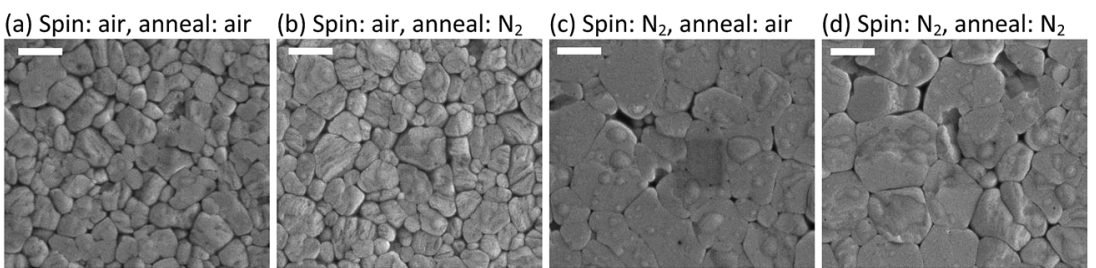

Fig. 2 Scanning electron microscopy (SEM) top view images of perovskite layers spin coated in air or $\mathrm{N}_{2}$ using the hot cast method and annealed in air or $\mathrm{N}_{2}$ as indicated above the images (scale bars are $1 \mu \mathrm{m}$ ). 

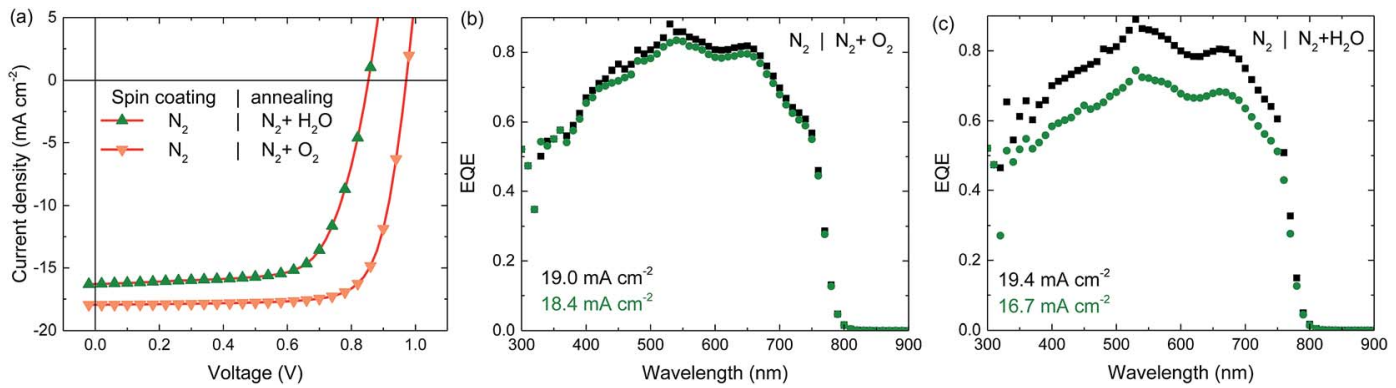

Fig. 4 Stabilized J-V curves (a) and EQE spectra ( $b$ and c) of perovskite solar cells spin coated in $\mathrm{N}_{2}$ using the hot cast method and annealed in dry air and humid $\mathrm{N}_{2}$ as indicated in the legends. Black squares depict the EQE under low charge carrier density (i.e. without bias illumination), green circles depict the EQE at a charge carrier density similar to that of the cell under 1 sun light intensity (i.e. with bias illumination). The integrated current density is displayed in the graphs for both measurements.

that the oxygen content of the air is the main reason for the performance increase. Table 1 summarizes the stabilized photovoltaic characteristics of these perovskite solar cells.

It is important to note that described sensitivity to oxygen during annealing is not exclusive to the hot-cast deposited perovskite layers. Identical results have been obtained for perovskite films deposited using a much more commonly used static casting at room temperature under inert circumstances. Also in this case films that are annealed in absence of oxygen show low $V_{\mathrm{OC}}$ and $J_{\mathrm{SC}}$ and bias light dependent EQEs (Fig. S5-S7 and Table S1, ESI $\dagger$ ).

Light intensity dependent $J_{\mathrm{SC}}$ measurements (Fig. 5a) show that the current generation of the $\mathrm{N}_{2}$-annealed samples is more sublinear $\left(J_{\mathrm{SC}} \propto I^{\alpha}\right.$, with $\left.\alpha<1\right)$ than that of air-annealed samples. Especially at higher light intensities the exponent $\alpha$ starts deviating from 1 , consistent with the results from the EQE measurements. From the light intensity dependent $V_{\mathrm{OC}}$ measurement (Fig. 5b), the ideality factor $(n)$ is calculated by determining the slope of the $V_{\mathrm{OC}}$ versus the logarithm of the light intensity in the linear part of the graph, ${ }^{46-48}$ where a slope equal to the thermal voltage $(-k T / q$ with $k$ the Boltzmann constant, $T$ the absolute temperature, and $q$ the elementary charge) represents an ideality factor of 1 . An ideality factor of $n=2$ indicates dominant trap-assisted recombination in the bulk, an ideality factor of 1 indicates purely bimolecular recombination. The higher slope at low light intensities is caused by recombination over shunt paths. ${ }^{48}$ The ideality factor determined using this method is about $n \approx 1.3$ for air-annealed cells, which would indicate a significant amount of trapassisted (Shockley-Read-Hall (SRH)) recombination. The ideality factor of the $\mathrm{N}_{2}$-annealed cells, however is about $n \approx 1$, which would suggest pure bimolecular recombination. However, the $V_{\mathrm{OC}}$ of this cell is lower than that of the air annealed cell, which should not be the case for an identical device with an ideality factor closer to unity. Strong surface recombination at a doped interface however, can reduce the ideality factor, making it appear to be closer to unity. ${ }^{49}$ Additionally, $V_{\mathrm{OC}} v s$. light intensity measurements using different illumination wavelengths ( $405 \mathrm{~nm}$ absorbed predominantly in the first $100 \mathrm{~nm}$ of the active layer seen from the PEDOT:PSS layer and $730 \mathrm{~nm}$ absorbed more uniformly through the active layer) show that the charge carrier generation profile inside the perovskite layer does not strongly influence the $V_{\mathrm{OC}}$ or the ideality factor. Together, these results suggest that the PEDOT:PSS/perovskite interface is a source of significant surface recombination in the $\mathrm{N}_{2}$-annealed perovskite cell at higher light intensities. ${ }^{48,50,51}$

As a next step, photoluminescence (PL) and electroluminescence (EL) measurements were conducted on air-annealed and $\mathrm{N}_{2}$-annealed layers and devices respectively. If the
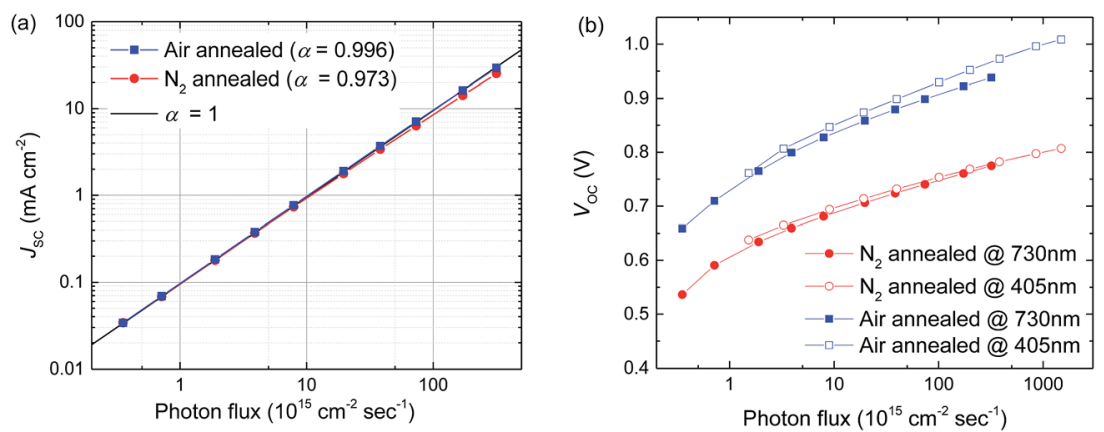

Fig. 5 (a) Light intensity dependent $J_{S C}$ of air-annealed (blue solid squares) and $\mathrm{N}_{2}$-annealed (red solid circles) perovskite solar cells (using an illumination wavelength of $730 \mathrm{~nm}$ ). A black line with an exponent $\alpha=1$ is added as a visual aid. (b) Light intensity dependent $V_{\mathrm{OC}}$ of air annealed (blue squares) and $\mathrm{N}_{2}$ annealed (red circles) perovskite solar cells measured using two different illumination wavelengths (730 nm solid symbols and $405 \mathrm{~nm}$ open symbols). The ideality factors $(n)$ calculated from the slopes of linear fit lines to the higher light intensity linear parts of the curves are $n \approx 1$ for $\mathrm{N}_{2}$-annealed cells and $n \approx 1.3$ for air-annealed cells. 
interface is indeed defective, the PL measurements should provide similar results for the air- and $\mathrm{N}_{2}$-annealed layers since the interfaces are not probed. In contrast, the EL measurements can show differences between the air- and $\mathrm{N}_{2}$-annealed perovskite cells, when charges build up near the injecting charge transport layers.

Room temperature and low temperature $(70 \mathrm{~K})$ photoluminescence results yield very similar results for the air- and $\mathrm{N}_{2}$-annealed perovskite layers (Fig. S8-S11, ESI $\dagger$ ). At room temperature the PL is dominated by a band at $1.60 \mathrm{eV}$, while at $70 \mathrm{~K}$ the emission peaks at $1.66 \mathrm{eV}$ together with a weak traprelated emission at $1.53 \mathrm{eV}$ (Fig. 6a). At $70 \mathrm{~K}$ there is no significant difference in peak shape and position at both medium and low illumination intensities and the relative intensity of the $1.53 \mathrm{eV}$ defect emission does not seem to increase (Fig. 6a). Electroluminescence external quantum efficiency (EL-EQE) measurements at room temperature show that the EL-EQE of perovskite layers annealed in air is higher than that of perovskite layers annealed in nitrogen (Fig. 6b), which holds up to high current densities $\left(>100 \mathrm{~mA} \mathrm{~cm}^{-2}\right)$. Because the current through the perovskite cells is similar for both annealing atmospheres (Fig S12, ESI $\dagger$ ), Fig. 6b indicates that the airannealed cells show electroluminescence at lower voltages, consistent with less traps that need to be filled before charges can recombine radiatively. In EL measurements at different voltages at room temperature and $70 \mathrm{~K}$, no significant differences could be found in peak shape and position (Fig. S13, ESI $\dagger$ ).

Combining the room- and low-temperature PL and EL results, we conclude that the improvement of the solar cell performance in the air-annealed perovskite layers is not primarily due to a change in the bulk properties of the perovskite layer.

We have shown that oxygen exposure during annealing is required for high performance solar cells and that likely the PEDOT:PSS/perovskite interface deteriorates when the perovskite layer is annealed in $\mathrm{N}_{2}$. It has been reported that PEDOT:PSS can be reduced (electro)chemically by the application of a voltage $\mathrm{e}^{52}$ or by exposure to polyethylenimine (PEI) ${ }^{53}$ and methylamine $(\mathrm{MA})^{54}$ vapour. In the latter case, the reduced PEDOT:PSS can be re-oxidized by exposure to oxygen. ${ }^{54}$ To investigate this effect in more detail, PEDOT:PSS layers were spin coated onto glass slides and perovskite layers were hot cast onto the PEDOT:PSS layers in a $\mathrm{N}_{2}$ atmosphere both using the same processing parameters as used for solar cell fabrication. The perovskite layers were then annealed, either in ambient air or in $\mathrm{N}_{2}$ and subsequently the perovskite layers were washed off from the underlying PEDOT:PSS layers using pure DMF. The resulting PEDOT:PSS layers were analysed and compared to fresh PEDOT:PSS layers using UV-vis-NIR spectroscopy (Fig. 7). The spectra show that the polaron absorption at $900 \mathrm{~nm}$ of the PEDOT:PSS layer that was underneath the $\mathrm{N}_{2}$-annealed perovskite layer, is higher than that of fresh PEDOT:PSS, and that the bipolaron band at wavelengths $\geq 1100 \mathrm{~nm}$ is lower in intensity (Fig. 7a). These are two clear signatures of chemical de-doping of PEDOT. ${ }^{54}$ In contrast, the UV-vis-NIR spectrum of the PEDOT:PSS layer that was underneath the air-annealed perovskite layer is very similar to the spectrum of the fresh PEDOT:PSS layer, apart from a narrow peak at $400 \mathrm{~nm}$. The onset and peak position of the $400 \mathrm{~nm}$ absorption coincides with the absorbance of orthorhombic lead oxide $(\mathrm{PbO})^{55}$ and triiodide $\left(\mathrm{I}_{3}{ }^{-}\right),{ }^{56}$ both of which could be present in the PEDOT:PSS film after deposition and washing off the perovskite layer. The presence of either of the two could however not be confirmed by XPS measurements.

To confirm that the de-doping of the PEDOT:PSS layer is reversible, the PEDOT:PSS layer that was underneath the $\mathrm{N}_{2}$ annealed perovskite layer was exposed to air. Air exposure of the de-doped PEDOT:PSS layer up to 180 minutes does indeed reoxidize the PEDOT, evidenced by a reduced polaron absorption at $900 \mathrm{~nm}$ and an increased bipolaron absorption above $1100 \mathrm{~nm}$. Annealing of the reduced PEDOT:PSS layer in air speeds up the re-oxidation reaction and prolonged air exposure almost completely re-oxidizes the PEDOT. XPS measurements for sulphur, carbon and oxygen on as cast and washed PEDOT:PSS layers do not show any significant difference in the composition of the material (Fig. S14, ESI $\dagger$ )

Ultraviolet photoelectron spectroscopy (UPS) measurements were performed on air- and $\mathrm{N}_{2}$-annealed perovskite layers and on the PEDOT:PSS layers that were underneath, after washing off the perovskite, to investigate the effect of the reduction and re-oxidation of the PEDOT:PSS layer on the electronic properties
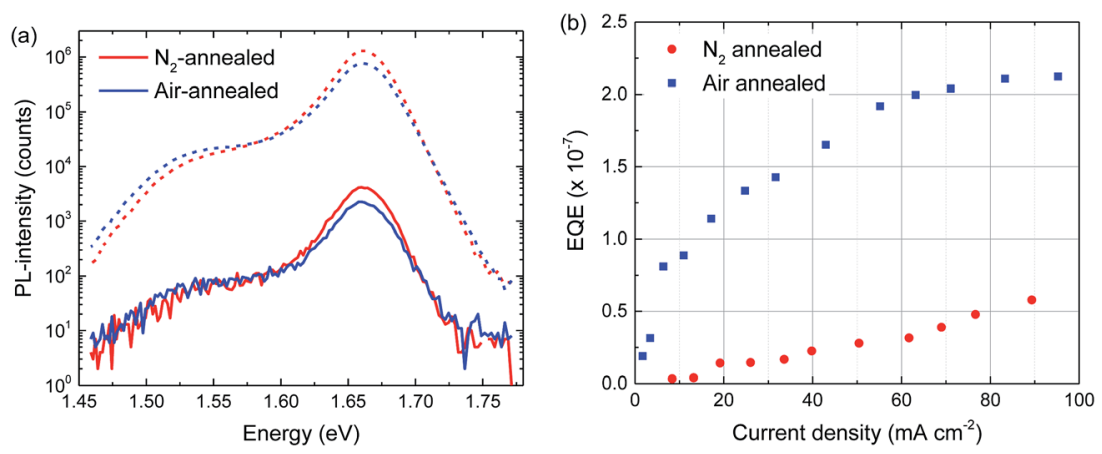

Fig. 6 (a) Photoluminescence spectra at $70 \mathrm{~K}$ of perovskite layers annealed in air (blue) and nitrogen (red) at high (dashed lines) and low (solid lines) illumination intensities. (b) EL-EQE measurements of solar cells with perovskite layers annealed in air (blue solid squares) and $\mathrm{N}_{2}$ (red solid circles). 

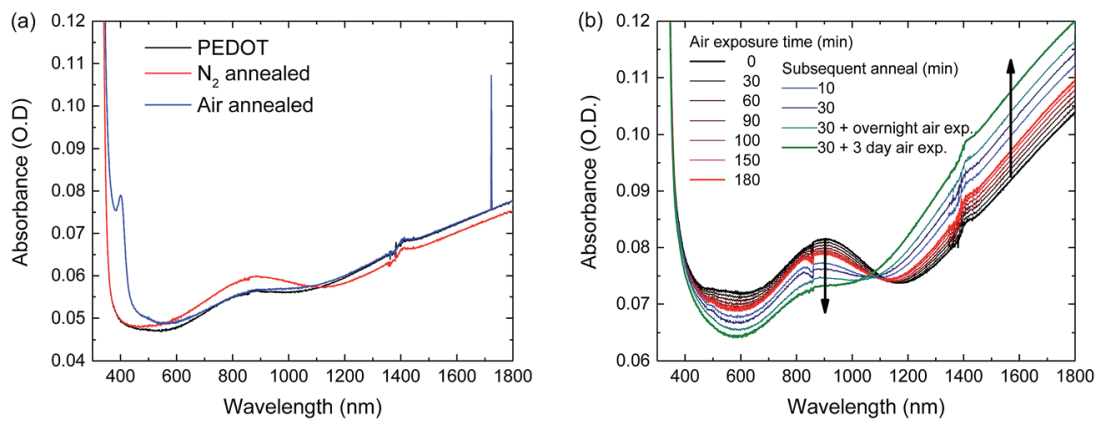

Fig. 7 (a) UV-vis-NIR spectra of a fresh PEDOT:PSS layer and PEDOT:PSS layers on which perovskite layers were deposited, annealed and washed off again. (b) UV-vis-NIR spectra of the PEDOT:PSS layer that was underneath the $\mathrm{N}_{2}$-annealed perovskite layer upon air exposure vs. time.
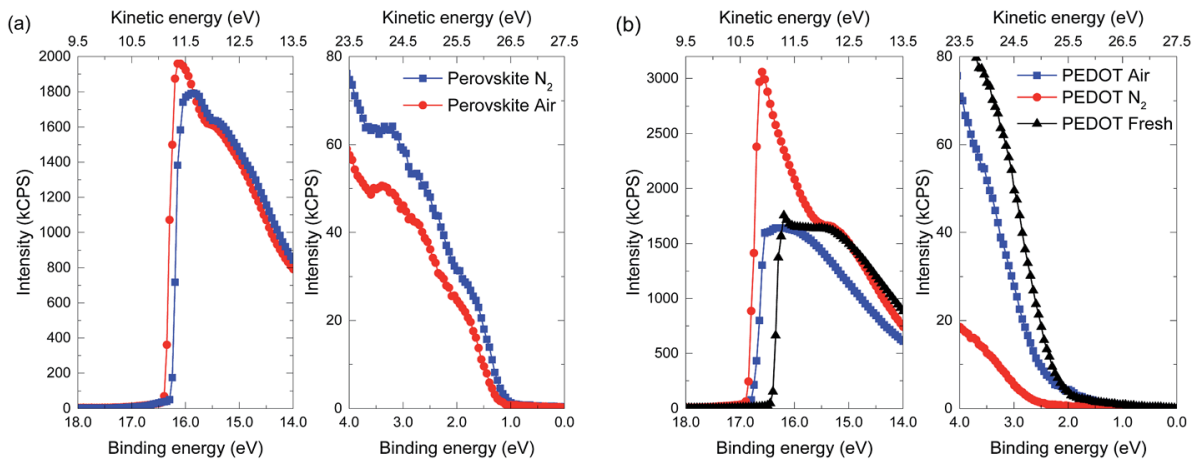

Fig. 8 UPS results of measurements on the top of a perovskite layer deposited onto PEDOT:PSS and annealed in air or nitrogen (a) and a fresh PEDOT:PSS layer and PEDOT:PSS layers that had a $\mathrm{N}_{2}$ or air annealed perovskite layer on top of them that has been washed off (b).

of the materials (Fig. 8 and Table 2). By comparing to UPS results for PEDOT:PSS, and PEDOT:PSS that was treated with DMF (Table 2), we see that just casting hot DMF on top of PEDOT:PSS already reduces both the work function (WF, Fermi energy) and ionization potential (IP, valence band energy) of a PEDOT:PSS layer. By subsequent washing with DMF at room temperature, a further decrease can be seen. The striking result is that with spin coating the perovskite precursor on

Table 2 UPS result summary of PEDOT:PSS and perovskite layers under different processing conditions

\begin{tabular}{lll}
\hline & $\begin{array}{l}\text { Workfunction } \\
(\mathrm{eV})\end{array}$ & $\begin{array}{l}\text { Ionization } \\
\text { potential } \\
(\mathrm{eV})\end{array}$ \\
\hline $\begin{array}{l}\text { Layer and processing } \\
\text { PEDOT:PSS }\end{array}$ & 4.83 & 5.06 \\
PEDOT:PSS|clean DMF hot cast & 4.48 & 4.83 \\
$\begin{array}{l}\text { PEDOT:PSS|clean DMF hot cast|DMF } \\
\text { wash }\end{array}$ & 4.40 & 4.65 \\
$\begin{array}{l}\text { PEDOT:PSS|perovskite hot cast|anneal } \\
\text { in } \mathrm{N}_{2} \mid \mathrm{DMF} \text { wash }\end{array}$ & 4.36 & 4.38 \\
$\begin{array}{l}\text { PEDOT:PSS|perovskite hot cast|anneal } \\
\text { in air|DMF wash }\end{array}$ & 4.48 & 4.47 \\
$\begin{array}{l}\text { PEDOT:PSS|perovskite hot cast|anneal } \\
\text { in } \mathrm{N}_{2}\end{array}$ & 4.84 & 6.10 \\
$\begin{array}{l}\text { PEDOT:PSS|perovskite hot cast|anneal } \\
\text { in air }\end{array}$ & 4.97 & 6.10
\end{tabular}

PEDOT:PSS, annealing and washing off of the perovskite layer from the PEDOT:PSS layer, the WF is equal to the IP. The other important observation is that the WF and IP of the PEDOT:PSS layer that was underneath a $\mathrm{N}_{2}$-annealed perovskite film is lower compared to the PEDOT:PSS layer that was underneath an air-annealed perovskite layer. Looking at the results of the perovskite layers deposited on PEDOT:PSS, we see a similar difference with the $\mathrm{N}_{2}$ annealed perovskite layer showing a lower WF than the air annealed one, while the IP of the two perovskite layers remains equal. This suggests that the WF of the perovskite layer is influenced by that of the PEDOT:PSS beneath it. It is worth to note that the difference between the WF of the PEDOT:PSS layer and that of the perovskite layer is similar $(\sim 0.5 \mathrm{eV})$ for both annealing atmospheres. The difference in the value of the WF of the perovskite layers results in a difference in the built-in voltage of the solar cells, allowing the $V_{\mathrm{OC}}$ of the air-annealed perovskite layer to exceed that of the $\mathrm{N}_{2}$ annealed cell. The difference in WF $(\sim 0.12 \mathrm{eV})$ is comparable to the difference in $V_{\mathrm{OC}}$ we measure in $J-V$ sweeps $(\sim 0.07 \mathrm{~V})$. The measured WFs and IPs for fresh PEDOT:PSS and the prepared perovskite layers are similar to previously reported values..$^{57,58}$

\section{Conclusions}

In this work we have shown that spin coating a perovskite precursor in DMF solution chemically reduces the oxidation 
state of the PEDOT:PSS hole transport layer on which it is deposited. The partial reduction of PEDOT:PSS from the highly oxidized bipolaron state to the polaron state, reduces the work function of the PEDOT:PSS whereby the work function becomes equal to the ionisation potential. The reduction in the work function of the PEDOT:PSS also reduces the work function of the perovskite layer that is positioned on top of it. Exposure of the reduced PEDOT:PSS to oxygen re-oxidizes the PEDOT:PSS. Even relatively short exposure (8 minutes) of the PEDOT:PSS layer during the annealing of the perovskite layer that is on top of it (partially) restores the oxidation state of the PEDOT and restores its functionality in the solar cell. The bulk properties of the perovskite layer do not seem to change by annealing in different atmospheres. Annealing the perovskite layers in an inert atmosphere therefore produces solar cells of inferior performance, displaying lower $V_{\mathrm{OC}}$ and a $J_{\mathrm{SC}}$ that is sublinear with light intensity compared to air-annealed devices.

\section{Experimental}

\section{Device fabrication}

Tin doped indium oxide (indium-tin oxide) (ITO) coated and pre-patterned glass substrates (Naranjo substrates) were cleaned by sonication in acetone (Sigma Aldrich), scrubbing in a solution of sodium dodecyl sulfate (SDS, Acros, 99\%) in filtered water (Milli-Q), rinsing in deionized water, sonication in 2-propanol (Sigma Aldrich) and 30 minutes of UV-ozone treatment right before use. Poly(3,4-ethylenedioxythiophene)poly(styrenesulfonate) (PEDOT:PSS, Heraeus Clevios PVP Al 4083) was filtered using a $0.45 \mu \mathrm{m}$ PVDF filter and spin coated (60 s, $3000 \mathrm{rpm})$ onto the cleaned substrates.

For the hot casting method, the PEDOT:PSS coated substrate was heated for 1 minute at $100{ }^{\circ} \mathrm{C}$ right before use, for the cold casting method, the PEDOT:PSS coated substrates were dried at $140{ }^{\circ} \mathrm{C}$ for 15 minutes. For the electron transport layer, PCBM (Solenne BV, 99\%) was dissolved in a 1:1 (v/v) mixture of chloroform (Biosolve, AR grade) and chlorobenzene (Sigma Aldrich, anhydrous $99.8 \%$ ) at $20 \mathrm{mg} \mathrm{mL}^{-1}$. The perovskite precursor solution for use with the hot casting method was prepared by weighing $476.9 \mathrm{mg}$ of methylammonium iodide (Dyesol), $303.5 \mathrm{mg}$ of lead(II) acetate trihydrate (Sigma Aldrich, 99.999\% trace metal basis) and $55.6 \mathrm{mg}$ of lead(II) chloride (Sigma Aldrich, 98\%) in air and adding $1 \mathrm{~mL}$ of $\mathrm{N}, \mathrm{N}$-dimethylformamide (Sigma Aldrich, anhydrous, 99.8\%). The mixture was stirred for 30 minutes at room temperature to completely dissolve all compounds and stirred at $70{ }^{\circ} \mathrm{C}$ for 30 minutes before use. The solution was then spin coated onto pre-heated $\left(100{ }^{\circ} \mathrm{C}\right) \quad$ PEDOT:PSS-covered substrates $(60 \mu \mathrm{L}, 20 \mathrm{~s}$, $5700 \mathrm{rpm}$, dynamic) using a specially designed spin coating chuck that minimizes contact between the substrate and the chuck to avoid rapid cooling of the substrate. The perovskite layer was then annealed immediately $\left(100{ }^{\circ} \mathrm{C}, 8\right.$ minutes) and after 1 minute of cooling, coated with PCBM (Solenne BV, 99\%) $(30 \mathrm{~s}, 1000 \mathrm{rpm})$. The device was then transferred into a glovebox, the contact area was cleaned and $\mathrm{LiF}(1 \mathrm{~nm})$ and $\mathrm{Al}$ $(100 \mathrm{~nm})$ were thermally evaporated under high vacuum $\left( \pm 3 \times 10^{-7}\right.$ mbar $)$ as a back electrode.
The perovskite precursor solution for use with the cold casting method was made by weighing $858.4 \mathrm{mg}$ of methylammonium iodide (Dyesol), $546.3 \mathrm{mg}$ of lead(II) acetate trihydrate (Sigma Aldrich, 99.999\% trace metal basis) and $100.1 \mathrm{mg}$ of lead(II) chloride (Sigma Aldrich, 98\%) and adding $1 \mathrm{~mL}$ of $\mathrm{N}, \mathrm{N}$-dimethylformamide (Sigma Aldrich, anhydrous, 99.8\%). The mixture was stirred for 30 minutes at room temperature to completely dissolve all the compounds. The solution was then spin coated onto the cleaned, PEDOT:PSS-coated and dried substrates $(60 \mu \mathrm{L}$, $120 \mathrm{~s}, 5700 \mathrm{rpm}$ ) using the same specially designed spin coating chuck. The perovskite layer was then annealed immediately (100 ${ }^{\circ} \mathrm{C}, 15$ minutes) and coated with PCBM (Solenne BV, 99\%) (30 s, $500 \mathrm{rpm})$. The device contact area was cleaned and LiF (1 $\mathrm{nm})$ and $\mathrm{Al}(100 \mathrm{~nm})$ were thermally evaporated under high vacuum $\left( \pm 3 \times 10^{-7} \mathrm{mbar}\right)$ as a back electrode.

To accurately control the temperature of the hotplate surfaces of different hotplates, aluminium slabs were used to achieve a homogeneous surface temperature and a surface temperature probe (Testo 05601109 mini surface thermometer) was used to measure the temperature. The mentioned temperatures are the temperatures set on the hotplate thermocouple. A set temperature of $100{ }^{\circ} \mathrm{C}$ corresponds to a temperature of $94{ }^{\circ} \mathrm{C}$ at the top of the aluminium slab measured with the surface probe.

\section{Measurement methods}

Layer thicknesses were measured using a Veeco Dektak 150 profilometer.

$J-V$ characteristics were measured in a nitrogen environment with a Keithley 2400 source meter under $\pm 100 \mathrm{~mW} \mathrm{~cm}^{-2}$ white light illumination from a tungsten-halogen lamp filtered by a Schott GG385 UV filter and a Hoya LB120 daylight filter. The cells were masked with a $0.0676 \mathrm{~cm}^{2}$ or $0.1296 \mathrm{~cm}^{2}$ aperture (the physical overlap of the contacts is $0.09 \mathrm{~cm}^{2}$ and $0.16 \mathrm{~cm}^{2}$ respectively) to avoid any underestimation of the active area due to the increased conductivity of the PEDOT:PSS layer by spin coating with DMF. The stabilized $J-V$ measurement protocol used was defined by light soaking at $V_{\text {OC }}$ for 5 minutes, followed by a downward sweep $\left(V_{\mathrm{OC}}+0.04 \mathrm{~V} \rightarrow-0.04 \mathrm{~V}\right)$ with a step size of $0.02 \mathrm{~V}$. At each voltage the current density was recorded for $10 \mathrm{~s}$ and the final value was used for plotting the $J-V$ curve. Fast upwards and downwards $J-V$ sweeps were performed before and after the slow sweep measurement between -0.5 and $1.5 \mathrm{~V}$ with a scan speed of $0.25 \mathrm{~V} \mathrm{~s}^{-1}$.

Short-circuit current densities under AM1.5G conditions were determined by integrating the spectral response with the solar spectrum. Spectral response measurements were conducted under only probe light and 1 sun equivalent operating conditions by using a $530 \mathrm{~nm}$ high power LED (Thorlabs M530L3 driven by a DC4104 driver) for bias illumination. The device was kept in a nitrogen filled box behind a quartz window and a circular aperture with a $1 \mathrm{~mm}$ radius and irradiated with modulated monochromatic light, from a 50 W tungstenhalogen lamp (Philips focusline) and monochromator (Oriel, Cornerstone 130) with the use of a mechanical chopper $(160 \mathrm{~Hz})$. The response was recorded as a voltage from 
a preamplifier (SR570) using a lock-in amplifier (SR830). A calibrated silicon cell was used as reference (calibrated at the Energy Research Centre of the Netherlands).

Scanning electron microscopy (SEM) was performed on a FEI Quanta 3D FEG.

Low intensity photoluminescence measurements were performed using an Edinburgh Instruments FLSP920 doublemonochromator luminescence spectrometer equipped with a multialkali photomultiplier tube and a nitrogen-cooled near IR sensitive photomultiplier (Hamamatsu). The substrate was positioned inside an Oxford Optistat cryostat under a dynamic vacuum. Cryogenic temperatures were achieved by indirectly cooling the substrate. The photoluminescence spectrometer has an internal uncalibrated photodetector to monitor the intensity of excitation beam of which the output is in counts per second. We have used a calibrated Si solar cell to calibrate the reference detector. The light from a xenon light source is monochromated to specific wavelengths for the PL measurements.

High intensity photoluminescence measurements were performed using a $532 \mathrm{~nm}$ laser (B\&W tek inc. BWN-532-20E/56486) excitation that was chopped using a mechanical chopper $(277 \mathrm{~Hz})$. The sample was located in an Oxford Optistat cryostat under dynamic vacuum. The signal was measured using a monochromator (Oriel 77700 at $775 \mathrm{~nm}$ ) and a Si diode linked to a lock-in amplifier (SR830DSP). The illumination intensity was varied using a double optical density filter wheel (New Focus 5215) and was calibrated at different OD settings using a Si photodiode. The illumination area of the laser beam was determined at different optical densities using a Gentec Beamage 3.0 beam diagnostic tool ( $1 / e^{2}$ value was used).

Electroluminescence measurements were performed in a nitrogen environment using a reference $\mathrm{Si}$ cell and two Keithley 2400 source meters to control the voltage and record the current flowing through the test cell and record the current flow out of the Si reference cell. Dividing the two current flows results in a crude electroluminescence external quantum efficiency value that is not absolute but can be used to compare samples measured in the same setup.

UPS measurements were performed in a multi-chamber ESCALAB II system using $6 \mathrm{~V}$ bias and the HeI line at $21.22 \mathrm{eV}$. The Fermi level reference was established on an in situ sputter-cleaned Au film. The ionization potential and the work function are derived from the energy difference between the secondary electron edge and, respectively, the valence band edge or the position of the Fermi energy. Samples were transferred from gloveboxes to the measurement equipment completely in an $\mathrm{N}_{2}$ atmosphere to avoid any effects of oxygen exposure. XPS measurements were performed with the same instrument using $\mathrm{Mg}(\mathrm{K} \alpha)$ radiation.

$V_{\mathrm{OC}} v s$. light intensity measurements were performed using a Keithley 2400 source meter and 405 and $730 \mathrm{~nm}$ high power LEDs (Thorlabs M405L3 and M730L4 driven by a DC4104 driver) for illumination.

\section{Conflicts of interest}

There are no conflicts to declare.

\section{Acknowledgements}

The research received funding from the European Research Council under the European Union's Seventh Framework Programme (FP/2007-2013)/ERC Grant Agreement No. 339031, forms part of the Solliance programme, and has received funding from the Ministry of Education, Culture and Science (Gravity program 024.001.035).

\section{References}

1 A. Kojima, K. Teshima, Y. Shirai and T. Miyasaka, J. Am. Chem. Soc., 2009, 131, 6050-6051.

2 H.-S. Kim, C.-R. Lee, J.-H. Im, K.-B. Lee, T. Moehl, A. Marchioro, S.-J. Moon, R. Humphry-Baker, J.-H. Yum, J. E. Moser, M. Grätzel and N.-G. Park, Sci. Rep., 2012, 2, 591.

3 M. M. Lee, J. Teuscher, T. Miyasaka, T. N. Murakami and H. J. Snaith, Science, 2012, 338, 643-648.

4 M. Saliba, T. Matsui, J.-Y. Seo, K. Domanski, J.-P. CorreaBaena, M. K. Nazeeruddin, S. M. Zakeeruddin, W. Tress, A. Abate, A. Hagfeldt and M. Grätzel, Energy Environ. Sci., 2016, 9, 1989-1997.

5 W. S. Yang, B.-W. Park, E. H. Jung, N. J. Jeon, Y. C. Kim, D. U. Lee, S. S. Shin, J. Seo, E. K. Kim, J. H. Noh and S. Il Seok, Science, 2017, 356, 1376-1379.

6 V. D'Innocenzo, G. Grancini, M. J. P. Alcocer, A. R. S. Kandada, S. D. Stranks, M. M. Lee, G. Lanzani, H. J. Snaith and A. Petrozza, Nat. Commun., 2014, 5, 3586.

7 L. M. Pazos-Outón, M. Szumilo, R. Lamboll, J. M. Richter, M. Crespo-Quesada, M. Abdi-Jalebi, H. J. Beeson, M. Vrućinić, M. Alsari, H. J. Snaith, B. Ehrler, R. H. Friend and F. Deschler, Science, 2016, 351, 1430-1433.

8 C.-S. Jiang, M. Yang, Y. Zhou, B. To, S. U. Nanayakkara, J. M. Luther, W. Zhou, J. J. Berry, J. Van De Lagemaat, N. P. Padture, K. Zhu and M. M. Al-jassim, Nat. Commun., 2015, 6, 8397.

9 C. Wehrenfennig, G. E. Eperon, M. B. Johnston, H. J. Snaith and L. M. Herz, Adv. Mater., 2014, 26, 1584-1589.

10 T. M. Schmidt, T. T. Larsen-Olsen, J. E. Carlé, D. Angmo and F. C. Krebs, Adv. Energy Mater., 2015, 5, 1500569.

11 K. Hwang, Y.-S. Jung, Y.-J. Heo, F. H. Scholes, S. E. Watkins, J. Subbiah, D. J. Jones, D.-Y. Kim and D. Vak, Adv. Mater., 2015, 27, 1241-1247.

12 Y. Galagan, E. W. C. Coenen, W. J. H. Verhees and R. Andriessen, J. Mater. Chem. A, 2016, 4, 5700-5705.

13 G. E. Eperon, S. D. Stranks, C. Menelaou, M. B. Johnston, L. M. Herz and H. J. Snaith, Energy Environ. Sci., 2014, 7, 982-988. 14 G. E. Eperon, G. M. Paternò, R. J. Sutton, A. Zampetti, A. A. Haghighirad, F. Cacialli and H. J. Snaith, J. Mater. Chem. A, 2015, 3, 19688-19695.

15 W. Liao, D. Zhao, Y. Yu, N. Shrestha, K. Ghimire, C. R. Grice, C. Wang, Y. Xiao, A. J. Cimaroli, R. J. Ellingson, N. J. Podraza, K. Zhu, R. G. Xiong and Y. Yan, J. Am. Chem. Soc., 2016, 138, 12360-12363.

16 J. H. Heo, D. H. Song, H. J. Han, S. Y. Kim, J. H. Kim, D. Kim, H. W. Shin, T. K. Ahn, C. Wolf, T. W. Lee and S. H. Im, Adv. Mater., 2015, 27, 3424-3430. 
17 C.-C. Chueh, C.-Y. Liao, F. Zuo, S. T. Williams, P.-W. Liang and A. K.-Y. Jen, J. Mater. Chem. A, 2015, 3, 9058-9062.

18 W. Zhang, M. Saliba, D. T. Moore, S. K. Pathak, M. T. Hörantner, T. Stergiopoulos, S. D. Stranks, G. E. Eperon, J. A. Alexander-Webber, A. Abate, A. Sadhanala, S. Yao, Y. Chen, R. H. Friend, L. A. Estroff, U. Wiesner and H. J. Snaith, Nat. Commun., 2015, 6, 6142.

19 K. L. Gardner, J. G. Tait, T. Merckx, W. Qiu, U. W. Paetzold, L. Kootstra, M. Jaysankar, R. Gehlhaar, D. Cheyns, P. Heremans and J. Poortmans, Adv. Energy Mater., 2016, 6, 1600386.

20 K. H. Hendriks, J. J. van Franeker, B. J. Bruijnaers, J. A. Anta, M. M. Wienk and R. A. J. Janssen, J. Mater. Chem. A, 2017, 5, 2346.

21 S. Bae, S. J. Han, T. J. Shin and W. H. Jo, J. Mater. Chem. A, 2015, 3, 23964-23972.

22 N. Ahn, D.-Y. Son, I.-H. Jang, S. M. Kang, M. Choi and N.-G. Park, J. Am. Chem. Soc., 2015, 137, 8696-8699.

23 N. K. Noel, S. N. Habisreutinger, B. Wenger, M. T. Klug, M. T. Hörantner, M. B. Johnston, R. J. Nicholas, D. T. Moore and H. J. Snaith, Energy Environ. Sci., 2017, 10, 145-152.

24 F. K. Aldibaja, L. Badia, E. Mas-Marzá, R. S. Sánchez, E. M. Barea and I. Mora-Sero, J. Mater. Chem. A, 2015, 3, 9194-9200.

25 G. Li, T. Zhang and Y. Zhao, J. Mater. Chem. A, 2015, 3, 19674-19678.

26 W. Qiu, T. Merckx, M. Jaysankar, C. Masse de la Huerta, L. Rakocevic, W. Zhang, U. W. Paetzold, R. Gehlhaar, L. Froyen, J. Poortmans, D. Cheyns, H. J. Snaith and P. Heremans, Energy Environ. Sci., 2016, 9, 484-489.

27 J. Qing, H.-T. Chandran, Y.-H. Cheng, X.-K. Liu, H.-W. Li, S.-W. Tsang, M.-F. Lo and C.-S. Lee, ACS Appl. Mater. Interfaces, 2015, 7, 23110-23116.

28 Z. Zhang, D. Wei, B. Xie, X. Yue, M. Li, D. Song and Y. Li, Sol. Energy, 2015, 122, 97-103.

29 B. Conings, A. Babayigit, M. T. Klug, S. Bai, N. Gauquelin, N. Sakai, J. T.-W. Wang, J. Verbeeck, H.-G. Boyen and H. J. Snaith, Adv. Mater., 2016, 28, 10701-10709.

30 N. J. Jeon, J. H. Noh, Y. C. Kim, W. S. Yang, S. Ryu and S. Il Seok, Nat. Mater., 2014, 13, 897-903.

31 J. Xiong, B. Yang, R. Wu, C. Caoa, Y. Huanga, C. Liu, Z. Hu, H. Huang, Y. Gao and J. Yang, Org. Electron., 2015, 24, 106-112.

32 M. Liu, M. B. Johnston and H. J. Snaith, Nature, 2013, 501, 395-398.

33 L. K. Ono, M. R. Leyden, S. Wang and Y. Qi, J. Mater. Chem. A, 2016, 4, 6693-6713.

34 Q. Chen, H. Zhou, Z. Hong, S. Luo, H.-S. Duan, H.-H. Wang, Y. Liu, G. Li and Y. Yang, J. Am. Chem. Soc., 2014, 136, 622625.

35 C. Wehrenfennig, M. Liu, H. J. Snaith, M. B. Johnston and L. M. Herz, Energy Environ. Sci., 2014, 7, 2269.

36 M. M. Tavakoli, L. Gu, Y. Gao, C. Reckmeier, J. He, A. L. Rogach, Y. Yao and Z. Fan, Sci. Rep., 2015, 5, 14083.

37 M. Saliba, K. W. Tan, H. Sai, D. T. Moore, T. Scott, W. Zhang, L. A. Estro, U. Wiesner and H. J. Snaith, J. Phys. Chem. C, 2014, 118, 17171-17177.
38 Y. Chen, Y. Zhao and Z. Liang, Chem. Mater., 2015, 27, 14481451.

39 S. R. Raga, M.-C. Jung, M. V. Lee, M. R. Leyden, Y. Kato and Y. Qi, Chem. Mater., 2015, 27, 1597-1603.

40 A. Dualeh, N. Tétreault, T. Moehl, P. Gao, M. K. Nazeeruddin and M. Grätzel, Adv. Funct. Mater., 2014, 24, 3250-3258.

41 Z. Xiao, Q. Dong, C. Bi, Y. Shao, Y. Yuan and J. Huang, Adv. Mater., 2014, 26, 6503-6509.

42 J. J. van Franeker, K. H. Hendriks, B. J. Bruijnaers, M. W. G. M. Verhoeven, M. M. Wienk and R. A. J. Janssen, Adv. Energy Mater., 2017, 7, 1601822.

43 G. E. Eperon, S. N. Habisreutinger, T. Leijtens, B. J. Bruijnaers, J. J. van Franeker, D. W. deQuilettes, S. Pathak, R. J. Sutton, G. Grancini, D. S. Ginger, R. A. J. Janssen, A. Petrozza and H. J. Snaith, ACS Nano, 2015, 9, 9380-9393.

44 C.-G. Wu, C.-H. Chiang, Z.-L. Tseng, M. K. Nazeeruddin, A. Hagfeldt and M. Grätzel, Energy Environ. Sci., 2015, 8, 2725-2733.

45 S. Pathak, A. Sepe, A. Sadhanala, F. Deschler, A. Haghighirad, N. Sakai, K. C. Goedel, S. D. Stranks, N. Noel, M. Price, S. Hüttner, N. A. Hawkins, R. H. Friend, U. Steiner and H. J. Snaith, ACS Nano, 2015, 9, 2311-2320.

46 L. J. A. Koster, V. D. Mihailetchi, R. Ramaker and P. W. M. Blom, Appl. Phys. Lett., 2005, 86, 1-3.

47 S. R. Cowan, A. Roy and A. J. Heeger, Phys. Rev. B: Condens. Matter Mater. Phys., 2010, 82, 245207.

48 K. Tvingstedt, L. Gil-Escrig, C. Momblona, P. Rieder, D. Kiermasch, M. Sessolo, A. Baumann, H. J. Bolink and V. Dyakonov, ACS Energy Lett., 2017, 2, 424-430.

49 K. Tvingstedt and C. Deibel, Adv. Energy Mater., 2016, 6, 1502230.

50 O. Malinkiewicz, A. Yella, Y. H. Lee, G. M. Espallargas, M. Graetzel, M. K. Nazeeruddin and H. J. Bolink, Nat. Photonics, 2014, 8, 128-132.

51 O. Bubnova, Z. U. Khan, H. Wang, S. Braun, D. R. Evans, M. Fabretto, P. Hojati-Talemi, D. Dagnelund, J.-B. Arlin, Y. H. Geerts, S. Desbief, D. W. Breiby, J. W. Andreasen, R. Lazzaroni, W. M. Chen, I. Zozoulenko, M. Fahlman, P. J. Murphy, M. Berggren and X. Crispin, Nat. Mater., 2013, 13, 190-194.

52 P. M. Beaujuge and J. R. Reynolds, Chem. Rev., 2010, 110, 268-320.

53 S. Fabiano, S. Braun, X. Liu, E. Weverberghs, P. Gerbaux, M. Fahlman, M. Berggren and X. Crispin, Adv. Mater., 2014, 26, 6000-6006.

54 T. Liu, F. Jiang, J. Tong, F. Qin, W. Meng, Y. Jiang, Z. Li and Y. Zhou, J. Mater. Chem. A, 2016, 4, 4305-4311.

55 R. C. Keezer, D. L. Bowman and J. H. Becker, J. Appl. Phys., 1968, 39, 2062-2066.

56 N. Li, L. Shi, X. Wang, F. Guo and C. Yan, Int. J. Anal. Chem., 2011, 130102.

57 P. Schulz, E. Edri, S. Kirmayer, G. Hodes, D. Cahen and A. Kahn, Energy Environ. Sci., 2014, 7, 1377.

58 S. Olthof and K. Meerholz, Sci. Rep., 2017, 7, 40267. 